\title{
Retinal and renal complications in patients with a mutation of mitochondrial DNA at position 3,243 (maternally inherited diabetes and deafness). A case-control study
}

\author{
P. Massin • D. Dubois-Laforgue $\cdot$ T. Meas • \\ M. Laloi-Michelin • H. Gin • B. Bauduceau • \\ C. Bellanné-Chantelot • E. Bertin • J.-F. Blickle • \\ B. Bouhanick $\cdot$ J. Cahen-Varsaux $\cdot$ S. Casanova $\cdot$ \\ G. Charpentier • P. Chedin • O. Dupuy • A. Grimaldi • \\ B. Guerci • E. Kaloustian • A. Lecleire-Collet • \\ F. Lorenzini • A. Murat • H. Narbonne $\cdot$ F. Olivier • \\ V. Paquis-Flucklinger $\cdot$ M. Virally $\cdot$ M. Vincenot $•$ \\ B. Vialettes • J. Timsit • P. J. Guillausseau • \\ for the GEDIAM (Mitochondrial Diabetes French \\ Study Group)
}

Received: 28 February 2008 / Accepted: 19 May 2008 / Published online: 26 June 2008

(C) Springer-Verlag 2008

\begin{abstract}
Aims/hypothesis We assessed the prevalence and determinants of retinal and renal complications in patients with maternally inherited diabetes and deafness (MIDD).
\end{abstract}

P. Massin and D. Dubois-Laforgue contributed equally to this study.

P. Massin · A. Lecleire-Collet

APHP, Department of Ophthalmology,

Lariboisiere Hospital,

University Paris 7 Denis-Diderot,

Paris, France

D. Dubois-Laforgue $\cdot$ J. Timsit

APHP, Department of Immuno-Diabetology,

Cochin Hospital,

University Paris 5 René-Descartes,

Paris, France

T. Meas • M. Laloi-Michelin • M. Virally •

P. J. Guillausseau $(\bowtie)$

Department of Internal Medicine B,

Hôpital Lariboisière,

2 Rue Ambroise Paré,

F 75475 Paris Cedex 10, France

e-mail: pierre-jean.guillausseau@1rb.aphp.fr

H. Gin

Department of Diabetology and Metabolism,

University Hospital,

Pessac, France
Methods This was a multicentre prospective study comparing the prevalence of retinopathy and renal disease in 74 patients with MIDD and 134 control patients matched for sex, age and clinical presentation at onset of diabetes, duration of diabetes and current treatment. Comparisons were adjusted for $\mathrm{HbA}_{1 \mathrm{c}}$ and hypertension.

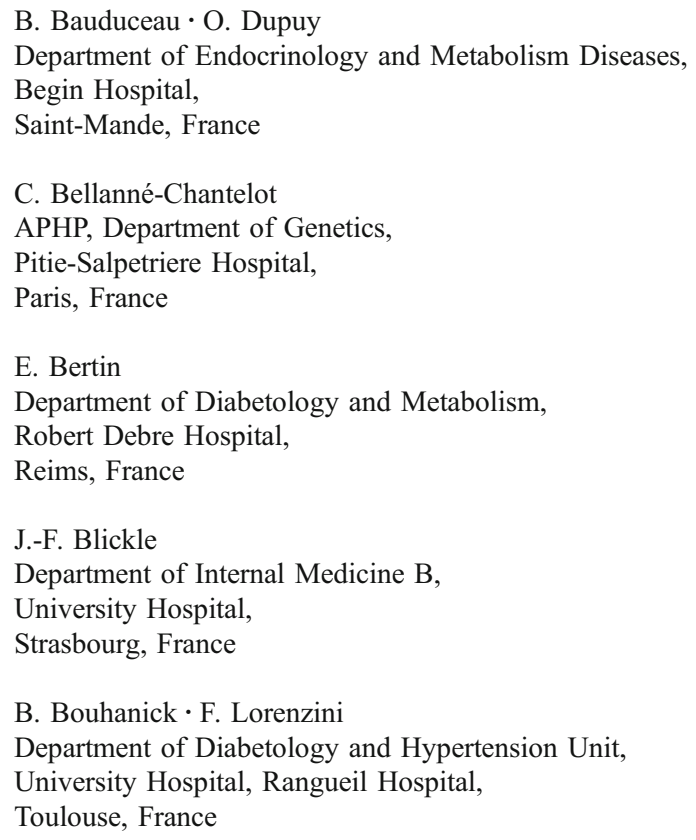


Results In MIDD patients, $\mathrm{HbA}_{1 \mathrm{c}}$ ( $7.6 \pm 1.6$ vs $8.5 \pm 2.0 \%, p<$ $0.002)$, systolic blood pressure $(126.6 \pm 16.2$ vs $133.1 \pm$ $17.3 \mathrm{mmHg}, p<0.007)$ and prevalence of hypertension (33.8 vs $64.2 \%, p<0.0001)$ were lower than in control patients. Prevalence of diabetic retinopathy was 3.7-fold lower in MIDD patients $(6 / 74,8$ vs 40/134, 29.6\%, $p<$ 0.0001). Differences between groups remained significant after adjustment for hypertension, systolic blood pressure and $\mathrm{HbA}_{1 \mathrm{c}}$. In MIDD, urinary albumin excretion (314.8 vs $80.1 \mathrm{mg} / 24 \mathrm{~h}, p=0.035)$ and creatinine plasma levels (103.5

J. Cahen-Varsaux $\cdot$ P. Chedin

Department of Diabetology and Metabolism,

General Hospital,

Argenteuil, France

S. Casanova

North Cardiology Centre,

Saint-Denis, France

G. Charpentier

Department of Diabetology,

Gilles-de-Corbeil Hospital,

Corbeil, France

A. Grimaldi

APHP, Department of Diabetology,

Pitie-Salpetriere Hospital,

Paris, France

B. Guerci

Department of Diabetology and Metabolism,

Jeanne-d'Arc Hospital,

Dommartin-les-Toul, France

E. Kaloustian

Department of Endocrinology and Metabolism Diseases, General Hospital,

Compiègne, France

\author{
A. Murat \\ Department of Endocrinology and Metabolism Diseases, \\ Hôtel-Dieu, \\ Nantes, France \\ H. Narbonne $\cdot$ B. Vialettes \\ Department of Diabetology and Metabolism, \\ La Timone Hospital, \\ Marseille, France \\ F. Olivier \\ Department of Diabetology, \\ General Hospital, \\ Cahors, France \\ V. Paquis-Flucklinger \\ Unit of Genetics, L'Archet Hospital, \\ Nice, France \\ M. Vincenot \\ Medical Centre, \\ Poissy, France
}

vs $82.2 \mu \mathrm{mol} / 1, p=0.0178)$ were higher and GFR was lower. Impaired renal function (GFR $<60 \mathrm{ml} / \mathrm{min}$ ) was four- to sixfold more frequent in MIDD. Differences between MIDD and control diabetic patients further increased when adjusted for $\mathrm{HbA}_{1 \mathrm{c}}$ and systolic blood pressure $(p<0.0001)$. Adjustment for treatment with an ACE inhibitor or angiotensin II receptor antagonist did not modify the results.

Conclusions/interpretation This study indicates that diabetic retinopathy is less prevalent in MIDD than in control diabetes. This suggests that retinal alterations due to mitochondrial disease may have a protective role. By contrast, nephropathy is far more frequent in MIDD, suggesting the presence of a specific renal disease independent of diabetic nephropathy.

Keywords Diabetes mellitus · Diabetic nephropathy · Macular pattern dystrophy · Maternally inherited diabetes and deafness · Mitochondrial 3243 mtDNA mutation . Mitochondrial nephropathy · Prevalence $\cdot$ Renal failure . Retinopathy
Abbreviations
ARA II angiotensin II receptor antagonist
MDRD Modification of Diet in Renal Disease
MIDD maternally inherited diabetes and deafness

\section{Introduction}

Maternally inherited diabetes and deafness (MIDD) is the type of diabetes most frequently related to mitochondrial disease. It is associated with a point mutation of mitochondrial DNA, an $\mathrm{A}$ to $\mathrm{G}$ transition at position $3243(\mathrm{~m} .3243 \mathrm{~A}>\mathrm{G})$ encoding for transfer RNA leucine (tRNA $\left.{ }^{\mathrm{Leu}[\mathrm{UUR}]}\right)[1,2]$. We previously reported the MIDD phenotype in 54 patients from a multicentre study [3] and found a low 7.5\% frequency of diabetic retinopathy, while kidney function was impaired in $75 \%$ of patients. We hypothesised that the retina was protected against microangiopathy/diabetic retinopathy by a reduction in oxygen requirements as a result of the specific pigmentary lesion, the so-called pattern dystrophy, which was present in $85 \%$ of these patients [3-5]. By contrast, in a series of Japanese patients with MIDD, a 13.4\% prevalence of pattern dystrophy and a $55 \%$ prevalence of diabetic retinopathy were observed [6].

The aim of the present study was thus to ascertain, in a larger series of Europid patients with MIDD, the prevalence of diabetic retinopathy and renal function abnormalities compared with that in patients with 'common' forms of diabetes matched for sex, age at onset, type, treatment and duration of diabetes. We also investigated the potential role of the other determinants of diabetic complications, i.e. high blood pressure and hyperglycaemia [7-9]. 


\section{Methods}

Patients The French Mitochondrial Diabetes Study Group (GEDIAM) multicentre prospective study [3] was initiated in September 1995. At the time of the study, 74 patients with MIDD (from 57 families) were included. All participants were Europid. The A3243G mutation was present in all of them. Diabetes was classified according to its clinical presentation at onset [10], i.e insulin-dependent $(n=12)$ and non-insulin-dependent $(n=62)$. Non-insulin-dependent diabetes was sub-classified, according to treatment at the time of the study, into insulin-requiring $(n=32)$ and noninsulin-treated diabetes $(n=30)$. These patients were compared with 134 unrelated patients with the 'common' subtypes of diabetes (type 1 and 2) recruited from the Department of Clinical Immunology and Diabetology of Cochin Hospital (Paris, France) and referred to as 'controls' in the present report. These control diabetic patients were free of the m.3243 $\mathrm{A}>\mathrm{G}$ mutation as well as of other monogenic diabetes, including MODY. Control diabetic patients were matched to patients with MIDD according to sex, age at onset of diabetes, clinical presentation at onset (i.e. insulin dependency or noninsulin dependency), duration of diabetes and current treatment (diet and/or glucose-lowering oral agents and/or insulin). Matching was performed with two controls for one patient with MIDD in 59 cases and with one control for one patient with MIDD in 16 cases (Table 1). The study conformed to the principles of the Declaration of Helsinki and participants gave informed consent.

Methods A structured interview and a standardised examination of the patients were used to ascertain family and personal history of diabetes, hearing loss, treatment, associated manifestations, and retinal and renal complications [3]. Diagnosis of diabetes was based on American Diabetes Association 1997 criteria [11]. $\mathrm{HbA}_{1 \mathrm{c}}$ was assayed by HPLC. Hypertension was defined as a blood pressure in excess of $140 / 85 \mathrm{mmHg}$ on two occasions after $10 \mathrm{~min}$ in the resting position or the use of antihypertensive treatment [12]. Of the control participants, 54 (42\%) versus 12 MIDD patients $(18 \% ; p<0.001)$ were being treated with an ACE inhibitor or angiotensin II receptor antagonist (ARA II). The $24 \mathrm{~h}$ urinary albumin excretion and plasma creatinine levels were determined. Glomerular filtration rate was calculated according to the Cockcroft and Gault formula [13], previously validated by our group in diabetic patients [14], and the Modification of Diet in Renal Disease (MDRD) equation [15]. Impaired renal function was defined as GFR $<60 \mathrm{ml} / \mathrm{min}$. A standardised ophthalmological examination was performed including colour fundus photographs in all cases and fluorescein angiography in some cases, with grading by the same investigator (P. Massin). The retinal epithelium alterations were graded according to published criteria $[4,5]$. Diabetic retinopathy was considered to be present if any characteristic lesion as defined by the Early Treatment Diabetic Retinopathy Study (ETDRS) severity scale [16] was present, i.e. microaneurysms, retinal haemorrhages, cotton wool spots, intraretinal microvascular abnormalities, hard exudates, venous beading, or new vessels. Diabetic retinopathy was classified using four grades of severity as follows: (1) no diabetic retinopathy; (2) background diabetic retinopathy for any signs of diabetic retinopathy less severe than severe nonproliferative diabetic retinopathy; (3) severe nonproliferative diabetic retinopathy with numerous peripheral retinal haemorrhages and/or moderate intraretinal microvascular anomalies and/or definite venous beadings; and (4) proliferative diabetic retinopathy with new vessels on the disc or elsewhere on the retina. Macular oedema was diagnosed from the presence of hard exudates within one disc diameter of the foveola.

Molecular studies As previously described, the m.3243 $\mathrm{A}>\mathrm{G}$ detection was based on an allele-specific PCR [17].

Statistical analysis Statistical analysis was performed using JMP (SAS Institute, Meylan, France). Data are expressed as means \pm 1 SD for continuous variables. Odds ratios are given with 95\% CI. Quantitative variables were compared using ANOVA in univariate analyses. The $\chi^{2}$ test was used for the comparison of class variables. Determinants of diabetic microvascular complications, either for retinopathy or nephropathy, were analysed using a linear multivariate model with the group (MIDD or control) as the explanatory variable, and $\mathrm{HbA}_{1 \mathrm{c}}$ and hypertension as covariates. Hypertension was entered into the model in two ways: (1) as a class variable, i.e presence or not of hypertension; and (2) as a continuous variable using systolic blood pressure. To proceed to the determinants of nephropathy, we also used a model including the variables already mentioned and the variable treated or not with an ACE inhibitor or ARA II.

\section{Results}

Data from the 74 patients with MIDD and the 134 diabetic controls are given in Tables 1 and 2. Patients with MIDD and controls were comparable for matching criteria. As previously reported $[1,3,6,10,18]$, mean BMI in the MIDD group was lower than in controls (Table 1). In patients with MIDD, mean $\mathrm{HbAl}_{c}$, mean systolic blood pressure (but not mean diastolic blood pressure) and prevalence of hypertension were lower than in controls (Table 2). Macular pattern dystrophy was present in 54/74 MIDD patients (73\%) and in none of the controls $(p<0.001)$. Deafness was present in 73 MIDD patients (98\%). 
Table 1 Characteristics of patients with MIDD and matched diabetic controls

\begin{tabular}{llll}
\hline Characteristic & MIDD & $\begin{array}{l}\text { Diabetic } \\
\text { controls }\end{array}$ & $p$ value \\
\hline$n$ & 74 & 134 & \\
$\begin{array}{l}\text { Women/men } \\
\text { Type of diabetes }\end{array}$ & $43 / 31$ & $81 / 53$ & 0.74 \\
$\begin{array}{l}\text { Non-insulin-dependent } \\
\text { Insulin-requiring }\end{array}$ & 28 & 56 & 0.96 \\
$\begin{array}{l}\text { Insulin-dependent } \\
\begin{array}{c}\text { Age at onset of } \\
\text { diabetes (years) }\end{array}\end{array}$ & 30 & 56 & \\
$\begin{array}{c}\text { Age at the time of } \\
\text { the study (years) }\end{array}$ & $48.5 \pm 9.1$ & $38.7 \pm 10.0$ & 0.38 \\
$\begin{array}{l}\text { Known duration } \\
\text { of diabetes (years) }\end{array}$ & $11.1 \pm 8.6$ & $10.9 \pm 8.1$ & 0.88 \\
\begin{tabular}{l} 
BMI $\left(\mathrm{kg} / \mathrm{m}^{2}\right.$ ) \\
\hline
\end{tabular} & $20.3 \pm 3.1$ & $29.3 \pm 6.0$ & $<0.0001$ \\
\hline
\end{tabular}

Results are expressed as $n$ or mean $\pm \mathrm{SD}$

Retinopathy Diabetic retinopathy was present in six patients with MIDD (8\%). Of these, five had background retinopathy, including a case with severe macular oedema involving the centre of the macula, and one had proliferative retinopathy. In the control group, retinopathy was observed in 40/134 patients (29.8\%), with a background form in 30 and a severe form in ten (five with severe pre-proliferative diabetic retinopathy and five with proliferative diabetic retinopathy). Nine of these ten cases had severe macular oedema involving the centre of the macula. Only two of the six MIDD patients with diabetic retinopathy had macular pattern dystrophy. Thus, diabetic retinopathy was nearly fourfold less frequent in patients with MIDD than in the control group (Table 3). In multivariate analysis, after adjustment for $\mathrm{HbA}_{1 \mathrm{c}}$ and systolic blood pressure or the presence or not of hypertension, differences between the two groups remained statistically significant (Table 3).

Nephropathy Data on urinary albumin excretion were not available in seven cases of MIDD and in one control case. Calculations were thus performed on 67 MIDD and 133 controls, whose clinical characteristics did not differ from the whole groups (data not shown). Mean urinary albumin excretion was increased in MIDD compared with control diabetic patients (Table 4). The number of patients with microalbuminuria, macroalbuminuria or normal urinary albumin excretion was comparable between the two groups, i.e. 33,11 and 88 in the control group subject, versus 20,10 and 37 in the MIDD group, respectively $(p=0.2)$. This result remained unchanged after adjustment for treatment with an ACE inhibitor or ARA II. In MIDD patients compared with controls (Table 4), creatinine plasma levels were higher and GFR (calculated according to either the Cockcroft and Gault formula or the MDRD equation) was lower. Impairment of renal function was 5- to 12-fold more frequent in MIDD than in controls, depending on the method used for GFR calculation. Differences were even greater when comparisons were adjusted for known determinants of diabetic nephropathy (hypertension and $\mathrm{HbA}_{1 \mathrm{c}}$, or systolic blood pressure and $\mathrm{HbA}_{1 \mathrm{c}}$ ), ranging from 14- to 20-fold in MIDD compared with controls. Adjustment for treatment with an ACE inhibitor or ARA II did not modify the results. Four patients from the MIDD group and none from the control group presented with end-stage renal failure, requiring either further renal transplantation or dialysis.

\section{Discussion}

The phenotype of MIDD is characterised by matrilineal transmission, early onset of diabetes (with either type 1 or type 2 presentation) and a low BMI. Hearing loss is observed in almost all cases, as well as macular pattern dystrophy, whose presence is almost specific to the disease at least in Europid patients. Cardiomyopathy, neuromuscular disorders and neuropsychiatric disturbances are also often associated with MIDD [3, 19]. Although we have previously reported a low frequency of diabetic retinopathy that contrasted with a high frequency of nephropathy [3], the prevalence of diabetic microvascular complications has not been systematically assessed in MIDD. In particular, the patients have not been compared with a control series of diabetic patients free of

Table 2 Determinants of diabetic microvascular complications in patients with MIDD and matched diabetic controls

\begin{tabular}{llll}
\hline Parameter & MIDD & Diabetic controls & $p$ value \\
\hline$n$ & 74 & 134 & 0.002 \\
$\mathrm{HbA}_{1 \mathrm{c}}(\%)$ & $7.6 \pm 1.6$ & $86(64.2)$ & 0.0001 \\
Hypertension & $25(33.8)$ & $133.1 \pm 17.3$ & 0.007 \\
Systolic blood pressure (mmHg) & $126.6 \pm 16.2$ & $76.0 \pm 8.9$ & 0.46 \\
Diastolic blood pressure (mmHg) & $77.0 \pm 10.4$ & \\
\hline
\end{tabular}

Results are expressed as $n(\%)$ or mean $\pm \mathrm{SD}$

Diabetic controls were matched for sex, age at onset of diabetes, clinical presentation at onset (i.e. insulin dependency or non-insulin dependency), duration of diabetes and current treatment 
Table 3 Prevalence of diabetic retinopathy in patients with MIDD and matched diabetic controls

\begin{tabular}{lcccccc}
\hline Parameter & $\begin{array}{l}\text { MIDD } \\
(n=74)\end{array}$ & $\begin{array}{l}\text { Diabetic controls } \\
(n=134)\end{array}$ & $\begin{array}{l}\text { Unadjusted } \\
\text { comparison }\end{array}$ & Model 1 & $p$ value & Model 2 \\
\hline Diabetic retinopathy & $6(8)$ & $40(29.8)$ & $p<0.0001$ & $3.2(1.3-9.0)$ & 0.017 & $3.3(1.3-9.7)$ \\
\hline
\end{tabular}

Results are expressed as $n(\%)$ or OR $(95 \% \mathrm{CI})$

Diabetic controls were matched for sex, age at onset of diabetes, clinical presentation at onset (i.e. insulin dependency or non-insulin dependency), duration of diabetes and current treatment

Multivariate comparisons were performed using two models. Model 1 compared the two groups (MIDD and diabetic controls) when adjusted for $\mathrm{HbA}_{1 \mathrm{c}}$ and the presence/absence of hypertension; model 2 compared the two groups after adjustment for $\mathrm{HbA}_{1 \mathrm{c}}$ and systolic blood pressure

MIDD and analysed according to major determinants of diabetic microangiopathy, i.e. glycaemic control and blood pressure.

The aim of the present study was thus to assess the prevalence of diabetic retinopathy and renal complications in patients with MIDD in comparison with that observed in patients with 'common' forms of diabetes matched for sex, age at onset, type and duration of diabetes. Comparisons between groups were adjusted for $\mathrm{HbA}_{1 \mathrm{c}}$ levels and hypertension. We found that the frequency of retinal complications due to diabetes was nearly fourfold lower, while renal complications were 6- to 14-fold more frequent in MIDD than in the 'common' forms of diabetes. Adjustment for treatment with an ACE inhibitor or ARA II did not modify the results.
Despite a mean duration of diabetes of 12 years, our patients exhibited a low frequency $(8 \%)$ of diabetic retinopathy. Studies in patients with common forms of diabetes have shown that retinopathy develops in approximately 30 to $50 \%$ of the patients after 10 to 12 year duration, according to disease subtype [20-24]. The prevalence of diabetic retinopathy observed in MIDD patients in the present series supports previous findings made in smaller series [25-28]. It should be pointed out that most of the patients from the series reported by other investigators had macular pattern dystrophy. This may explain the apparent discrepancy between our results and those from a Japanese series [6], where diabetic retinopathy was frequent $(55 \%$ of the cases), but macular pattern dystrophy was rare (13\%).

Table 4 Renal values as indicated in patients with MIDD and matched diabetic controls

\begin{tabular}{|c|c|c|c|c|c|c|}
\hline Parameter & $\begin{array}{l}\text { Urinary albumin } \\
\text { excretion } \\
(\mathrm{mg} / 24 \mathrm{~h})\end{array}$ & $\begin{array}{l}\text { Plasma creatinine } \\
(\mu \mathrm{mol} / 1)\end{array}$ & $\begin{array}{l}\text { GFR Cockcroft } \\
(\mathrm{ml} / \mathrm{min})\end{array}$ & $\begin{array}{l}\text { GFR MDRD } \\
(\mathrm{ml} / \mathrm{min})\end{array}$ & $\begin{array}{l}\text { Impaired renal } \\
\text { function Cockcroft }{ }^{\mathrm{a}} \text {, } \\
n(\%)\end{array}$ & $\begin{array}{l}\text { Impaired renal } \\
\text { function } \mathrm{MDRD}^{\mathrm{a}} \text {, } \\
n(\%)\end{array}$ \\
\hline $\operatorname{MIDD}(n=67)$ & $314.8 \pm 869$ & $103.5 \pm 70.3$ & $64.5 \pm 23.9$ & $74.5 \pm 26.9$ & $31(46.3)$ & $20(29.8)$ \\
\hline $\begin{array}{l}\text { Diabetic controls } \\
(n=133)\end{array}$ & $80.1 \pm 29$ & $82.2 \pm 19.4$ & $102.4 \pm 32.1$ & $82.4 \pm 18.1$ & $9(6.8)$ & $10(7.5)$ \\
\hline $\begin{array}{l}\text { Unadjusted } \\
\text { comparison }\end{array}$ & & & & & $11.86(5.4-26.6)$ & $5.23(2.3-12.4)$ \\
\hline$p$ value & 0.035 & 0.0178 & $<0.0005$ & 0.032 & $<0.0001$ & $<0.0001$ \\
\hline Model 1 & & & & & $15.9(6.1-41.3)$ & $6.0(2.5-15.5)$ \\
\hline$p$ value & 0.005 & 0.002 & $<0.001$ & 0.007 & $<0.001$ & $<0.001$ \\
\hline Model 2 & & & & & $14.7(6.0-39.9)$ & $7.4(2.9-20.0)$ \\
\hline$p$ value & & & & & $<0.0001$ & $<0.001$ \\
\hline Model 3 & & & & & $19.1(7.6-54.7)$ & $10.5(4.0-30.9)$ \\
\hline$p$ value & & & & & $<0.0001$ & $<0.001$ \\
\hline Model 4 & & & & & $15.9(6.7-43.9)$ & $6.5(3.1-17.0)$ \\
\hline$p$ value & & & & & $<0.001$ & $<0.001$ \\
\hline Model 5 & & & & & $19.2(7.0-60.7)$ & $8.6(3.3-24.2)$ \\
\hline$p$ value & & & & & $<0.001$ & $<0.001$ \\
\hline
\end{tabular}

Results are expressed as $n(\%)$, mean \pm SD or OR $(95 \% \mathrm{CI})$

Diabetic controls were matched for sex, age at onset of diabetes, clinical presentation at onset (i.e. insulin dependency or non-insulin dependency), duration of diabetes and current treatment

Multivariate comparisons were performed using several models. Model 1 compared the two groups after adjustment for treatment with an ACE inhibitor or ARA II; Model 2 compared the groups after adjustment for $\mathrm{HbA}_{1 \mathrm{c}}$ and presence or not of hypertension; Model 3 compared the groups after adjustment for $\mathrm{HbA}_{1 \mathrm{c}}$ and systolic $\mathrm{BP}$; Model 4 compared the groups after adjustment for $\mathrm{HbA}_{1 \mathrm{c}}$, presence or not of hypertension and treatment with an ACE inhibitor or ARA II; Model 5 compared the groups after adjustment for $\mathrm{HbA}_{1 \mathrm{c}}$, systolic $\mathrm{BP}$, presence or not of hypertension and treatment with an ACE inhibitor or ARA II

${ }^{\mathrm{a}}<60 \mathrm{ml} / \mathrm{min}$ 
The main known risk factors for diabetic retinopathy are high plasma glucose [7, 9, 21] and hypertension [8]. Systolic blood pressure and $\mathrm{HbA}_{1 \mathrm{c}}$ were lower in patients with MIDD than in controls, but differences in the prevalence of diabetic retinopathy between the two groups remained significant after adjustment for these risk factors. This suggests the presence of protective factors against diabetic retinopathy in MIDD. Some ocular factors, such as high myopia, amblyopia and retinitis pigmentosa, are known to provide a protective effect $[29,30]$, but they were absent in our patients. It is widely accepted that protection by such factors occurs through a reduction in retinal metabolism, a decrease in oxygen needs, the production of vasoproliferative factors and/or a reduced retinal blood flow [31]. The same mechanism(s) may underlie the low prevalence of retinopathy in MIDD patients, as alterations of pigment epithelium were present in $73 \%$ of the patients from our series. Several anatomical and electrophysiological studies have shown that retinal dysfunction extends beyond the alterations observed by fundus examination [26, $32,33]$. Such a generalised retinal dysfunction may result in reduced retinal metabolism and oxygen demand, and constitute a relative protection against diabetic retinopathy. Mitochondrial dysfunction in the retina may also result in decreased production of superoxide, which is considered to be a causal link between elevated glucose and the major biochemical pathways involved in the development of diabetic microvascular complications [34].

In contrast with the low prevalence of retinopathy, MIDD patients exhibited a high prevalence of kidney disease. Albumin excretion rate and creatinine plasma levels were higher, and GFR lower in MIDD patients than in control diabetic participants. In the latter, the prevalence of abnormal urinary albumin excretion was consistent with that described in common forms of diabetes with the same disease duration $[7,9]$. Overall, renal dysfunction was observed in $53.7 \%$ of MIDD patients compared with $28.5 \%$ in diabetic controls. Moreover, differences between groups increased after adjustment for hypertension and glycaemic control. One may thus hypothesise that renal impairment in MIDD patients is more likely to be a result of specific mitochondrial defects than of hyperglycaemia and/or hypertension. Indeed, renal disease is commonly observed early in the course of mitochondrial cytopathies, generally occurring before the emergence of diabetes [35]. Specific clinical and pathological renal features [36-38] have been described in patients with mitochondrial cytopathies, with no histological change indicative of diabetic nephropathy, even though patients presented with diabetes $[35,38,39]$.

In conclusion, our data indicate that diabetic retinopathy is less prevalent in MIDD patients than in a control group with 'common' forms diabetes. This better retinal prognosis in MIDD might result from protective specific retinal alterations due to mitochondrial dysfunction. By contrast, nephropathy is much more frequent in MIDD than in 'common' forms of diabetes, suggesting the role of a specific mitochondrial kidney disease, leading to a more severe renal prognosis in MIDD patients. In these patients, early renal protection should be proposed.

Acknowledgements We wish to thank C. Donagh for her help in the preparation of the manuscript.

Duality of interest The authors declare that there is no duality of interest associated with this study.

\section{References}

1. Van den Ouweland JMW, Lemkes HHPJ, Ruittenbeek W et al (1992) Mutation in mitochondrial tRNA ${ }^{\text {Leu(UUR) }}$ gene in a large pedigree with maternally transmitted type II diabetes mellitus and deafness. Nat Genet 1:368-371

2. Reardon W, Ross RJM, Sweeney MG et al (1992) Diabetes mellitus associated with a pathogenic point mutation in mitochondrial DNA. Lancet 340:1376-1379

3. Guillausseau PJ, Massin P, Dubois-Laforgue D et al (2001) Maternally inherited diabetes and deafness: a multicenter survey. Ann Intern Med 134:721-728

4. Massin P, Guillausseau PJ, Vialettes B et al (1995) Macular pattern dystrophy associated with a mutation of mitochondrial DNA. Am J Ophthalmol 120:247-248

5. Massin P, Virally-Monod M, Vialettes B et al (1999) Prevalence of macular pattern dystrophy in maternally inherited diabetes and deafness. Ophthalmology 106:1821-1827

6. Suzuki S, Oka Y, Kadowaki T et al (2003) Clinical features of diabetes mellitus with the mitochondrial DNA 3243 (A-G) mutation in Japanese: maternal inheritance and complications. Diab Res Clin Pract 59:207-217

7. UK Prospective Diabetes Study (UKPDS) Group (1998) Intensive blood-glucose control with sulphonylureas or insulin compared with conventional treatment and risk of complications in patients with type 2 diabetes (UKPDS 33). Lancet 352:837-853

8. UK Prospective Diabetes Study Group (1998) Tight blood pressure control and risk of macrovascular and microvascular complications in type 2 diabetes: UKPDS 38. BMJ 317:703-713

9. The Diabetes Control and Complications Trial Research Group (1993) The effect of intensive treatment of diabetes on the development and progression of long-term complications in insulin-dependent diabetes mellitus. N Engl J Med 329:977-986

10. Guillausseau PJ, Dubois-Laforgue D, Massin P et al (2004) Heterogeneity of diabetes phenotype in patients with $3243 \mathrm{bp}$ mutation of mitochondrial DNA (maternally inherited diabetes and deafness). Diabetes Metab 30:181-186

11. The Expert Committee on the Diagnosis and Classification of Diabetes Mellitus (1997) Report of the Expert Committee on the diagnosis and classification of diabetes mellitus. Diabetes Care 20:1183-1197

12. Joint National Committee on Prevention, Detection, Evaluation, and Treatment of High Blood Pressure (1997) Sixth report. Arch Intern Med 157:2413-2446

13. Cockroft DW, Gault MH (1976) Prediction of creatinine clearance from serum creatinine. Nephron 16:31-41

14. Guillausseau PJ, Fontbonne A, Cahen-Varsaux J, Moulonguet M, Papoz L, Lubetzki J (1988) Creatinine clearance evaluation in routine diabetes practice. Diabetes Res Clin Exp 7:145-148 
15. Levey AS, Bosch JP, Lewis JB, Greene T, Rogers N, Roth D (1999) A more accurate method to estimate glomerular filtration rate from serum creatinine: a new prediction equation. Modification of Diet in Renal Disease Study Group. Ann Intern Med 130:461-470

16. Early Treatment Diabetic Retinopathy Study Research Group (1991) Grading diabetic retinopathy from stereoscopic color fundus photographs. An extension of the modified Airlie House classification. ETDRS report number 10. Ophthalmology 98:786-806

17. Guéry B, Choukroun G, Noel LH et al (2003) The spectrum of systemic involvement in adults presenting with renal lesion and mitochondrial tRNA(Leu) gene mutation. J Am Soc Nephrol 14:2099-2108

18. Maassen JA, Kadowaki T (1996) Maternally inherited diabetes and deafness: a new diabetes subtype. Diabetologia 39:375-382

19. Vialettes B, Paquis-Fluckinger V, Silvestre-Aillaud P et al (1995) Extra-pancreatic manifestations in diabetes secondary to mitochondrial DNA point mutation within the ${ }_{t} \mathrm{RNA}{ }^{\text {leu(UUR) }}$ gene. Diabetes Care 18:1023-1028

20. Klein R, Klein BEK, Moss SE, Cruickshanks KJ (1994) The Wisconsin Epidemiologic Study of Diabetic Retinopathy. XIV. Ten-year incidence and progression of diabetic retinopathy. Arch Ophthalmol 112:1217-1228

21. Guillausseau PJ, Massin P, Charles MA et al (1998) Glycaemic control and development of retinopathy in type 2 diabetes: a longitudinal study. Diabet Med 15:151-155

22. Wong TY, Klein R, Amirul Islam FM et al (2007) Three-year incidence and cumulative prevalence of retinopathy: the atherosclerosis risk in communities study. Am J Ophthalmol 143:970-976

23. Younis N, Broadbent DM, Vora JP, Harding SP (2003) Incidence of sight-threatening retinopathy in patients with type 2 diabetes in the Liverpool Diabetic Eye Study: a cohort study. Lancet 361:195-200

24. Younis N, Broadbent DM, Harding SP, Vora JP (2003) Incidence of sight-threatening retinopathy in type 1 diabetes in a systematic screening programme. Diabet Med 20:758-765

25. Bonte C, Leys A, Matthijs G, Missotten L (1996) Fundus changes in patients with the mitochondrial DNA point mutation at position 3243. Bull Soc Belge Ophtalmol 261:9-12

26. Smith PR, Bain SC, Good PA et al (1999) Pigmentary retinal dystrophy and the syndrome of maternally inherited diabetes and deafness caused by the mitochondrial DNA 3243 tRNA(Leu) A to G mutation. Ophthalmology 106:1101-1108

27. Katagiri H, Asano T, Ishihara $\mathrm{H}$ et al (1994) Mitochondrial diabetes mellitus: prevalence and clinical characterization of diabetes due to mitochondrial tRNALeu(UUR) gene mutation in Japanese patients. Diabetologia 37:504-510

28. Holmes-Walker DJ, Mitchell P, Boyages SC (1998) Does mitochondrial genome mutation in subjects with maternally inherited diabetes and deafness decrease severity of diabetic retinopathy? Diabet Med 1:946-952

29. Arden GB (2001) The absence of diabetic retinopathy in patients with retinitis pigmentosa: implications for pathophysiology and possible treatment. Br J Ophthalmol 85:366-370

30. Jais IS, Luthra CL, Das T (1967) Diabetic retinopathy and its relation to errors of refraction. Ophthalmology 77:59-60

31. Weiter JJ, Zuckerman R (1980) The influence of photoreceptorRPE complex on the inner retina: an explanation for the beneficial effects of photocoagulation. Ophthalmology 87:11331139

32. Chang TS, Johns DR, Walker D, de la Cruz Z, Maumence IH, Green WR (1993) Ocular clinicopathologic study of the mitochondrial encephalomyopathy overlap syndromes. Arch Ophthalmol 111:1254-1262

33. Rummelt V, Folberg R, Ionasescu V, Yi H, Moore KC (1993) Ocular pathology of MELAS syndrome with mitochondrial DNA 3243 point mutation. Ophthalmology 100:1757-1766

34. Brownlee M (2001) Biochemistry and molecular cell biology of diabetic complications. Nature 414:813-820

35. Nakamura S, Yoshinari M, Doi Y et al (1999) Renal complications in patients with diabetes mellitus associated with an A to $G$ mutation of mitochondrial DNA at the position 3243 of leucine tRNA. Diab Res Clin Pract 44:183-189

36. Hotta O, Inoue CN, Miyabayashi S, Furuta T, Takeuchi A, Taguma Y (2001) Clinical and pathological features of focal segmental glomerulosclerosis with mitochondrial tRNA ${ }^{\text {Leu (UUR) }}$ gene mutation. Kidney Int 59:1236-1243

37. Moulonguet-Doléris L, Hill GS, Chedin P et al (2000) Focal segmental glomerulosclerosis associated with mitochondrial cytopathy. Kidney Int 58:1851-1858

38. Hirano M, Konishi K, Arata N et al (2002) Renal complications in a patient with A-to-G mutation of mitochondrial DNA at the 3243 position of leucine tRNA. Int Med 41:113-118

39. Iwasaki N, Babazono T, Tsuchiya K et al (2001) Prevalence of Ato-G mutation at nucleotide 3243 of the mitochondrial tRNA (Leu (UUR)) gene in Japanese patients with diabetes mellitus and end stage renal disease. J Hum Genet 46:330-334 